\title{
Ultrafiltração na remoção de glifosato e ácido aminometilfosfônico em águas de abastecimento
}

\author{
Ultrafiltration for removal of glyphosate and \\ aminomethylphosphonic acid in drinking water
}

Edumar Ramos Cabral Coelho** ${ }^{1 *}$, Dariene Patricia Reis'

口

\begin{abstract}
RESUMO
O glifosato é um herbicida não seletivo utilizado no controle de ervas daninhas em ambientes agrícolas e urbanos. É encontrado em mananciais associado ao seu principal metabólito, o ácido aminometilfosfônico, sendo necessária a remoção destes em estações de tratamento de água. O objetivo do trabalho foi avaliar a ultrafiltração direta na rejeição do glifosato e do ácido aminometilfosfônico em água de manancial superficial fortificada nas concentrações de 630, 800 e 1.250 $\mu \mathrm{g} \mathrm{L} \mathrm{L}^{-1}$ e variação de pH entre 4 e 10. Para o glifosato, os aumentos do pH e da concentração e a presença de matéria orgânica natural contribuíram para a taxa de rejeição. A massa de glifosato adsorvida foi de $1,2 \mu \mathrm{g} \mathrm{cm}$, sendo a adsorção na superfície e nos poros da membrana o principal mecanismo de rejeição. A ultrafiltração direta não foi efetiva para rejeição do ácido aminometilfosfônico. Para concentração

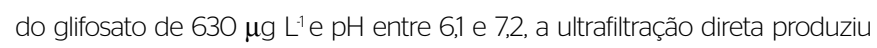
permeado com concentração inferior a $500 \mu \mathrm{g} \mathrm{L} \mathrm{L}^{-1}$, atendendo ao padrão de potabilidade brasileiro, Portaria Gabinete do Ministro/Ministério da Saúde no 888, publicada em 7 de maio de 2021.
\end{abstract}

Palavras-chave: ultrafiltração; glifosato; ácido aminometilfosfônico; herbicida; tratamento de água de abastecimento.

\begin{abstract}
Glyphosate is a non-selective herbicide used to control weeds in agricultural and urban environments. It is found in water sources associated with its main metabolite, the aminomethylphosphonic acid, and it must be removed in the public water treatment. The aim of this work was to evaluate the direct ultrafiltration in the removal of glyphosate and aminomethylphosphonic acid in fortified surface water at concentrations of 630, 800, and 1,250 $\mu \mathrm{g} \mathrm{L}^{-1}$ and $\mathrm{pH}$ variation between 4 and 10. For glyphosate, the increase in $\mathrm{pH}$, concentration, and the presence of natural organic matter contributed to the rejection rate. The herbicide mass adsorbed was $1.2 \mu \mathrm{g} \mathrm{cm}{ }^{2}$, being adsorption onto the membrane surface/pores the main mechanism of herbicides retention. The UF process was not effective for removal of aminomethylphosphonic acid. For glyphosate concentration of $630 \mu \mathrm{g} \mathrm{L} \mathrm{L}^{-1}, \mathrm{pH}$ of 6.1-7.2, the UF was effective to produce the permeated in concentration of less than $500 \mu \mathrm{g} \mathrm{L}^{-1}$, as recommended by the Brazilian Drinking Water Legislation of the Ministry of Health, Portaria Gabinete do Ministro/Ministério da Saúde no 888, publicada em 7 de maio de 2021.
\end{abstract}

Keywords: ultrafiltration; glyphosate; aminomethylphosphonic acid; herbicide; drinking water treatment.

\section{INTRODUÇÃO}

O glifosato (N-(fosfonometil)glicina) é o herbicida mais comercializado no mundo para aplicar em área urbana e na agricultura, com registro em mais de 160 países (MONSANTO, 2016). No ano de 2018, comercializaram-se 195.056,02 toneladas do glifosato no Brasil, sendo utilizado nas culturas de soja, milho, algodão, laranja, eucalipto, em rodovias e jardins públicos (HANKE et al., 2010; IBAMA, 2016). Seu uso é polêmico em todo o mundo e, no Brasil, está sendo reavaliado pela Agência Nacional de Vigilância Sanitária (ANVISA, 2017).

O mais importante produto de biodegradação do glifosato é o ácido aminometilfosfônico (AMPA), encontrado no ambiente também como resultado de fotodegradação de produtos amino-polisulfonados como detergentes e anticorrosivos. Em estudo realizado por Battaglin et al. (2003) nos Estados Unidos, em 51 mananciais próximos à área agrícola, a presença de glifosato e AMPA foi detectada em concentrações de 8,7 e 100,0 $\mu \mathrm{g} \mathrm{L}^{-1}$, respectivamente. Na Itália, as concentrações mais elevadas de agrotóxicos em águas de superfície têm sido referentes ao AMPA, da ordem de $200 \mu \mathrm{g} \mathrm{L}^{-1}$ (MEFFE \& BUSTAMANTE, 2014). No estado do Rio Grande do Sul, o glifosato foi detectado em concentração acima de $100 \mu \mathrm{g} \mathrm{L}$ - $^{-1}$ (SILVA, PERALBA \& MATTOS, 2003). Os limites máximos permitidos em água para abastecimento público são diferentes em vários países. A Organização Mundial da Saúde (OMS) não recomenda valor limite para glifosato e AMPA, e na União Europeia o limite é de $0,1 \mu \mathrm{g} \mathrm{L}{ }^{-1}$ para qualquer tipo de ingrediente ativo. Nos Estados Unidos e na

'Universidade Federal do Espírito Santo - Vitória (ES), Brasil.

*Autor correspondente: edumar.coelho@ufes.br

Conflitos de interesse: os autores declaram não haver conflitos de interesse.

Financiamento: O projeto foi financiado pela Financiadora de Estudos e Projetos (FINEP) sob o número 0973/10.

Recebido: 30/03/2O19 - Aceito: 14/09/2O2O - Reg. ABES: 20200101 
China, o limite máximo para o glifosato é de $0,7 \mu \mathrm{g} \mathrm{L}^{-1}$. No Brasil, a Portaria Gabinete do Ministro/Ministério da Saúde (GM/MS) no 888 , de 4 de maio de 2021, estabelece limite de $500 \mu \mathrm{g} \mathrm{L}^{-1}$ para a somatória de glifosato e AMPA (BRASIL, 2017). Na Argentina, não existe padrão limite estabelecido para o glifosato, sendo encontrado em mananciais em concentrações elevadas, com valores entre 200 e $1.600 \mu \mathrm{g} \mathrm{L}^{-1}$ (AVIGLIANO \& SCHENONE, 2015).

O impacto do glifosato em células humanas dá-se por interferência no DNA, no desenvolvimento de células cancerígenas, na mutagenicidade e efeitos na reprodução e no sistema endócrino (GASNIER et al., 2009). A toxicidade do AMPA mostra-se igual ou superior à do próprio glifosato (WILLIAMS et al., 2000).

A molécula do glifosato é altamente polar, possui massa molar de $169,05 \mathrm{~g} \mathrm{~mol}^{-1}$, solubilidade em água de $10,5 \mathrm{~g} \mathrm{~L}^{-1}$ a $20^{\circ} \mathrm{C}$, elevado coeficiente de adsorção no solo e baixo coeficiente de partição octanol/água (log Kow) de $<5,4$. O glifosato apresenta constante de dissociação ácida (pKa) entre 2,00 e 10,86, e o número de cargas negativas aumenta com o aumento do $\mathrm{pH}$ (AMARANTE JUNIOR et al., 2002). Como o glifosato, o AMPA é também polar, possui massa molar de $111,04 \mathrm{~g} \mathrm{~mol}^{-1}$ e solubilidade acima de $58 \mathrm{~g} \mathrm{~L}^{-1}$ a $20^{\circ} \mathrm{C}, \log$ Kow de $<2,3$. Em água pode aparecer protonado ou não, pois possui diferentes valores de pKa entre 0,9 e 10,2 (GRANDCOIN et al., 2017). Na Figura 1, encontram-se as estruturas químicas do glifosato e do AMPA.

Como o glifosato e o AMPA estão presentes em águas de mananciais, é necessária a remoção destes pelos processos de tratamento de água. Jönsson, Rob e Hall (2013) apresentaram artigo de revisão avaliando a remoção do glifosato e do AMPA em sistemas de tratamento de água, e, de acordo com os autores, as remoções por coagulação, por carvão ativado e por UV são limitadas, e o processo de separação por membranas apresenta-se como uma tecnologia alternativa.

O processo de ultrafiltração é empregado em tratamento de água para rejeição de matéria orgânica, microrganismos, toxinas de cianobactérias e agrotóxicos (YOON et al., 2006; MIERZWA et al., 2008; CHEN et al., 2019; SANTOYO et al., 2020).

A rejeição de microcontaminantes no processo de membranas pode ocorrer por exclusão por tamanho, repulsão eletrostática ou adsorção. Considerando que a massa molar de corte das membranas de ultrafiltração varia de 10.000 a $100.000 \mathrm{~g} \mathrm{~mol}^{-1}$, valores esses muito superiores à massa molar dos microcontaminantes (próximo a $100 \mathrm{~g} \mathrm{~mol}^{-1}$ ), os mecanismos de rejeição ficam restritos à repulsão eletrostática ou à adsorção.

A previsão de rejeição de microcontaminantes em água natural é difícil, pois depende das propriedades da membrana e do microcontaminante de interesse, das interações membrana soluto e das características da matriz de alimentação (KIM et al., 2018). Segundo Yoon et al. (2006), a adsorção de microcontaminantes na superfície da membrana de ultrafiltração está relacionada ao log Kow. A presença de matéria orgânica natural (MON) contribui significativamente para o decréscimo na permeabilidade da membrana ao longo do tempo pela formação de<smiles>O=C(O)CNCP(=O)(O)O</smiles>

glifosato

AMPA: ácido aminometilfosfônico. Fonte: Grandcoin et al. (2017).

Figura 1 - Estruturas químicas do glifosato e do ácido aminometilfosfônico. depósitos sobre a membrana (UYAK et al., 2014). E ainda, segundo Barbot et al. (2008), a operação do processo por meio do fluxo tangencial minimiza a colmatação e a formação desses depósitos. Speth (1993) estudou a rejeição de glifosato, para concentração inicial de $350 \mu \mathrm{g} \mathrm{L} \mathrm{L}^{-1}$, por ultrafiltração em membranas com peso molar de corte de 500, 1.000 e $100.000 \mathrm{~g} \mathrm{~mol}^{-1}$ e verificou rejeição de 100 , 50 e $0 \%$ para as respectivas membranas. Poucos estudos consideram a remoção do glifosato e do AMPA por ultrafiltração, e, por esse motivo, estudos em instalações de laboratório são o primeiro passo para definir a capacidade da membrana em reter os microcontaminantes com vistas à aplicação posterior em escala real.

O objetivo principal deste estudo foi avaliar a rejeição do glifosato e do AMPA em instalação de ultrafiltração direta considerando a influência do $\mathrm{pH}$, da variação na concentração e da presença de $\mathrm{MON}$ para produção de água para consumo humano em conformidade com a Portaria GM/MS no 888/2021 (BRASIL, 2021).

\section{METODOLOGIA}

\section{Água de estudo}

O glifosato e o AMPA foram adicionados em água destilada e água de manancial superficial (água natural) com o objetivo de avaliar a influência da MON no processo de ultrafiltração.

As soluções de glifosato e AMPA foram preparadas semanalmente com base em padrões sólidos da Sigma Aldrich, com pureza de 99\%, em água ultrapura obtida com o sistema MILI-Q (Millipore), em concentração de $10 \mathrm{mg} \mathrm{L}^{-1}$. Para prevenir perdas, as soluções foram preparadas instantes antes da filtração e armazenadas em geladeira a $4^{\circ} \mathrm{C}$, em frascos âmbar.

\section{Métodos analíticos}

A caracterização da água de alimentação e do permeado foi feita por meio dos seguintes parâmetros: cor aparente e verdadeira, $\mathrm{pH}$, turbidez e absorvância-UV $254 \mathrm{~nm}$, de acordo com o Standard Methods for the Examination of Water and Wastewater (APHA, 2012).

Para quantificar o glifosato e o AMPA, utilizou-se um sistema cromatográfico iônico modular da marca DIONEX, modelo ICS 3.000. A coluna analítica foi a AS 23 (de $250 \mathrm{~mm}$ de comprimento, $2 \mathrm{~mm}$ de diâmetro e 6 micrômetros de diâmetro de partícula), coluna de guarda AG 23 (50 mm de comprimento, $2 \mathrm{~mm}$ de diâmetro e 11 micrômetros de diâmetro de partícula), coluna supressora de alta resistência ASRS 300 II e detector de condutividade. Os padrões de calibração para glifosato e AMPA foram preparados com base nos padrões adquiridos com a Sigma Aldrich, ambos com pureza superior a 99\%. Inicialmente os padrões de $1.000 \mu \mathrm{g} \mathrm{mL}^{-1}$ de ambos os analitos foram preparados dissolvendo o padrão sólido em água deionizada e degaseificada de modo a se ter uma solução de alta estabilidade. As soluções de referência concentradas foram então armazenadas em frascos de vidro cada um separadamente sob refrigeração. O fluxo de eluente na cromatografia foi de $0,38 \mathrm{~mL} \mathrm{~min}^{-1}$, a temperatura da coluna de $25^{\circ} \mathrm{C}$ e do detector de $35^{\circ} \mathrm{C}$. Os limites de quantificação para glifosato e AMPA foram determinados injetando soluções de mesma concentração do padrão por sete vezes e por inspeção do coeficiente de variação percentual, que, para ambos, foi abaixo de $5 \%$, o que torna aceitável a quantificação. O limite de quantificação foi de $0,10 \mu \mathrm{g} \mathrm{mL}^{-1}$ para glifosato e $0,25 \mu \mathrm{g} \mathrm{mL}^{-1}$ para AMPA. A metodologia empregada foi a desenvolvida por Santos et al. (2013). 


\section{Unidade de filtração e procedimento experimental}

O trabalho experimental consistiu em utilizar uma membrana de geometria cilíndrica do tipo fibra oca de polietersulfona (hidrofóbica) com massa molar de corte de $50 \mathrm{KDa}$ e área de filtração de $0,059 \mathrm{~m}^{2}$. De acordo com o fabricante, a pressão máxima de operação da instalação é de 5 bar, a temperatura máxima de $55^{\circ} \mathrm{C}$, o pH pode variar entre 2 e 13 e a permeabilidade hidráulica da membrana é de $42,25 \mathrm{~L} \mathrm{~h}^{-1} \mathrm{~m}^{-2}$.

Os ensaios foram realizados para avaliar a capacidade do sistema de ultrafiltração na rejeição glifosato e AMPA em água destilada e água natural com variação do tempo, da concentração e do $\mathrm{pH}$.

A instalação operou no modo de filtração tangencial, sentido de fora para dentro, com alimentação do módulo de membrana por bomba diafragma. $\mathrm{O}$ concentrado retornava para o tanque de alimentação. Monitoraram-se os seguintes parâmetros: vazão e concentração do permeado e do concentrado, concentração na alimentação e pressão do sistema. A lavagem física das membranas era efetuada após o encerramento de cada ensaio. A Figura 2 apresenta o diagrama da instalação de ultrafiltração.

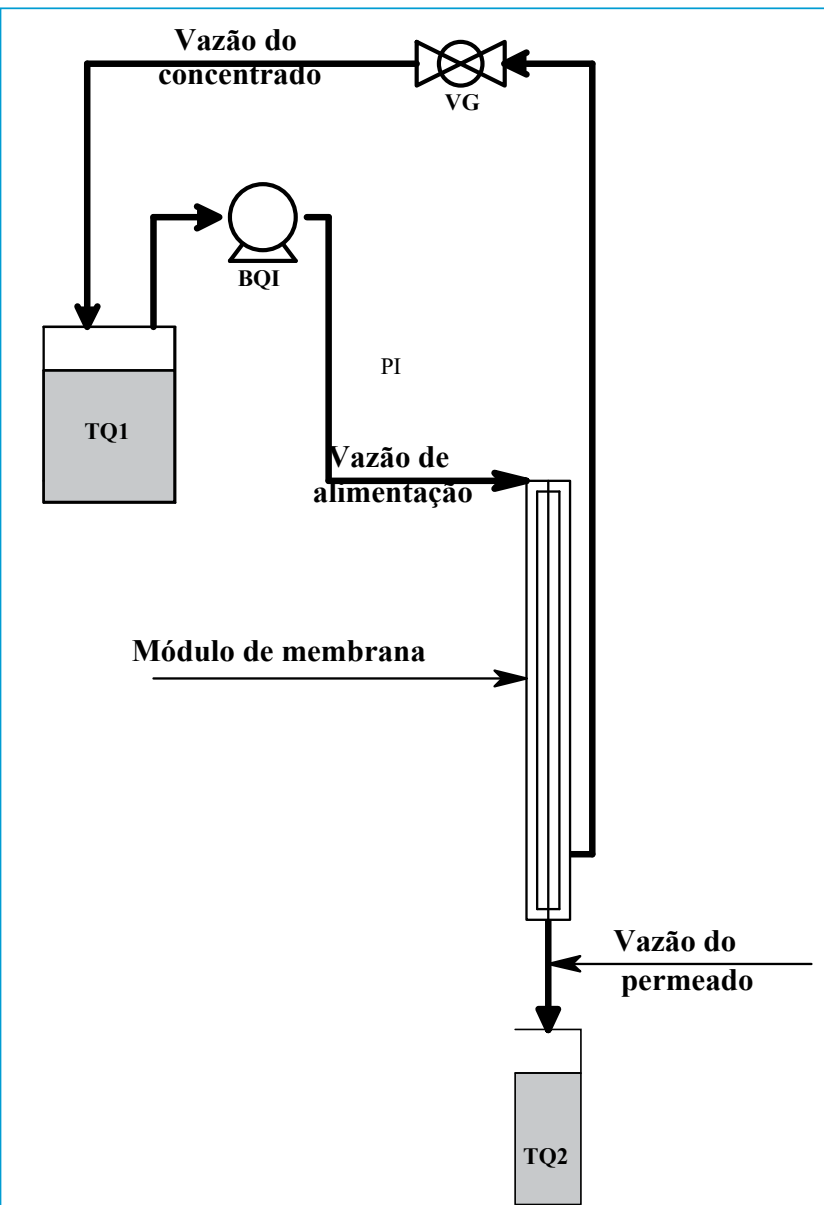

TQ1: tanque de alimentação, 10 L; TQ2: tanque de permeado, 5 L; BQI: bomba diafragma; UF: módulo de membrana de fibra oca; PI: indicador pressão; VG: válvula de gaveta.

Fonte: elaboração própria

Figura 2 - Esquema da instalação.
O estudo foi dividido em duas etapas: a primeira de testes preliminares e a segunda de operação com água natural de manancial superficial. As condições operacionais de pressão e tempo de operação foram estabelecidas na etapa de testes preliminares com alimentação da instalação com água destilada e concentração de $630 \mu \mathrm{g} \mathrm{L^{-1 }}$.

O ensaio com água natural permitiu a simulação de uma condição real em sistemas de abastecimento público. A coleta da água de manancial superficial realizou-se sempre no dia dos ensaios. A água natural foi contaminada com as soluções de glifosato e AMPA para produzir concentrações de 630, 800 e $1.250 \mu \mathrm{g} \mathrm{L}^{-1}$. A variação do $\mathrm{pH}$ esteve entre 4, $\mathrm{pH}$ natural (definido como o pH da água do manancial superficial que variou entre 6,1 e 7,2) e 10, respeitando o limite estabelecido pelo fabricante da membrana entre 2 e 13 . O ajuste do pH na solução de alimentação foi realizado empregando-se a solução diluída $0,1 \mathrm{~mol} \mathrm{~L}^{-1}$ de ácido clorídrico para atingir o $\mathrm{pH}$ de 4 , e solução diluída de hidróxido de sódio $0,1 \mathrm{~mol} \mathrm{~L}^{-1}$ para ajuste de $\mathrm{pH}$ de 10 . O estudo do efeito do pH na rejeição do glifosato e do AMPA é importante pela ionização das moléculas em diferentes pHs.

A permeabilidade hidráulica foi obtida passando pela membrana água ultrapura com variação de pressão entre 0,5 e 3,0 bar à temperatura de $25 \pm 2{ }^{\circ} \mathrm{C}$ para produção de um volume conhecido. Para medir o volume, utilizou-se a pipeta acoplada ao equipamento e mediu-se o tempo para produzir um volume de $9 \mathrm{~mL}$ de permeado para cada valor de pressão utilizado. Os valores encontrados permitiram a construção da curva de fluxo do permeado versus pressão, e a permeabilidade hidráulica foi determinada pelo coeficiente angular da reta encontrada.

A permeabilidade hidráulica da membrana foi verificada após cada ensaio depois da limpeza física ou química. A limpeza física consistia na lavagem da tubulação e dos tanques com água e sabão neutro, seguida de passagem de água destilada por 30 minutos. A limpeza química foi realizada a cada 5 horas e consistia na passagem de solução de hipoclorito de sódio na concentração de $500 \mathrm{mg} \mathrm{L}^{-1} \mathrm{em}$ água destilada durante uma hora, de acordo com recomendações do fabricante, após, era sempre realizada uma limpeza física.

A capacidade da membrana quanto à produção de fluxo foi determinada conforme Equação 1. A capacidade de rejeição do glifosato e do AMPA pelas membranas representada por $\mathrm{R}$ foi determinada pela Equação 2, e o balanço de massas para avaliar a rejeição foi dado pela Equação 3.

$J o=\frac{V}{A t}$

$R=\left(\frac{C a-C p}{C a}\right) 100$

$Q a C a=Q p C p+Q c C c$

Em que:

$J o=$ fluxo de permeado $\left(\mathrm{L} \mathrm{h}^{-1} \mathrm{~m}^{-2}\right)$;

$V=$ volume coletado $(\mathrm{L})$;

$A$ = área efetiva da membrana $\left(\mathrm{m}^{2}\right)$;

$t=$ tempo de coleta $(\mathrm{h})$;

$R=$ porcentagem de rejeição;

$C a ; C p ; C c=$ concentração do contaminante na alimentação, no permeado e no concentrado $\left(\mu \mathrm{g} \mathrm{L}^{-1}\right)$;

$Q a, Q p$ e $Q c=$ vazão de alimentação, no permeado e no concentrado $\left(\mathrm{L} \mathrm{h}^{-1}\right)$. 


\section{RESULTADOS E DISCUSSÃO}

O equipamento de ultrafiltração operou no modo tangencial com fixação de pressão de 2 bar (mantendo dessa forma pressão constante e fluxo variável), temperatura ambiente entre $25 \pm 2^{\circ} \mathrm{C}$ e tempo de operação de 40 minutos.

O ensaio em água destilada foi realizado com adição individual de glifosato e AMPA na concentração de $630 \mu \mathrm{g} \mathrm{L}^{-1} \mathrm{e} \mathrm{pH}$ 7. Esse ensaio foi importante para comparar e avaliar a influência da MON na rejeição do glifosato e do AMPA em água natural. As coletas do permeado foram realizadas a cada 10 minutos, e o resultado está apresentado na Figura 3.

Observou-se rejeição parcial dos contaminantes, apesar da membrana possuir massa molar de corte $\left(50.000 \mathrm{~g} \mathrm{~mol}^{-1}\right)$ muito superior à massa molar do glifosato $\left(169,05 \mathrm{~g} \mathrm{~mol}^{-1}\right)$ e do AMPA $\left(111,04 \mathrm{~g} \mathrm{~mol}^{-1}\right)$. A rejeição máxima do glifosato e do AMPA ocorreu nos primeiros 10 minutos com estabilização a partir de 20 minutos. De acordo com Santos (2013), a estabilização ocorre pela polarização da concentração na superfície da membrana com transporte difusivo no sentido de remover o excesso da superfície da membrana de volta para a solução. Quando o equilíbrio é atingido, a massa de contaminante que sofreu difusão da membrana para a solução e a massa que atravessa a membrana se mantêm constantes, e a variação de concentração no permeado será reduzida no decorrer do tempo. Segundo Lautenschlager et al. (2009), os sistemas de ultrafiltração operam em intervalos de tempo entre 30 e 90 minutos. O tempo estabelecido para os ensaios foi de 40 minutos, e nessa condição a concentração do glifosato no permeado

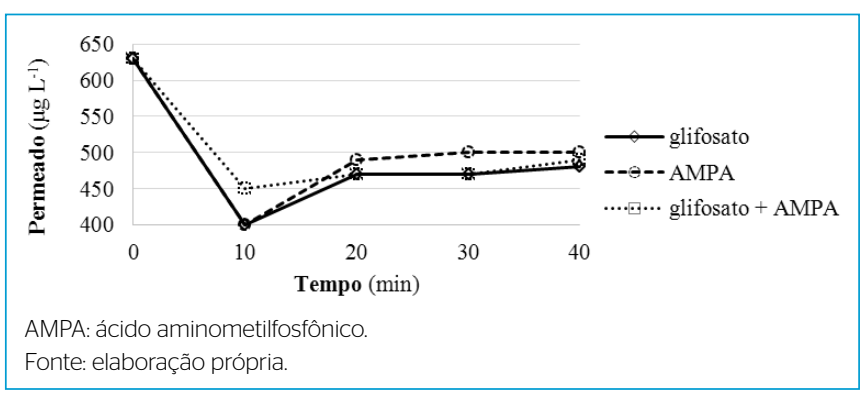

Figura 3 - Concentração do glifosato e do ácido aminometilfosfônico $\left(\mu \mathrm{g} \mathrm{L}^{-1}\right)$ no permeado em função do tempo de operação (min) em água destilada (pressão de 2 bar e concentração inicial do glifosato e do ácido aminometilfosfônico de $\left.630 \mu \mathrm{g} \mathrm{L}^{-1}\right)$. foi de $480 \mu \mathrm{g} \mathrm{L}^{-1} \mathrm{e}$ a do AMPA de $500 \mu \mathrm{g} \mathrm{L}^{-1}$, com taxa de recuperação de 24 e $21 \%$, respectivamente.

Para os ensaios em água de manancial superficial, avaliaram-se as condições de: adição do glifosato e do AMPA separadamente e a associação destes, variação de concentração do glifosato e do AMPA e variação de pH. O glifosato e o AMPA foram adicionados nas concentrações de 630, 800 e $1.250 \mu \mathrm{g} \mathrm{L}^{-1}$. Nos ensaios com a mistura de glifosato e AMPA, cada solução contribuiu com metade das concentrações de referência de 630,800 e $1.250 \mu \mathrm{g} \mathrm{L}^{-1}$. A variação do $\mathrm{pH}$ ficou estabelecida para o valor de $4, \mathrm{pH}$ natural (entre 6,1 e 7,2) e pH de 10. Na Tabela 1, estão apresentados os parâmetros de qualidade da água de alimentação (água natural), do permeado e os valores máximos permitidos (VMP) na Portaria GM/MS nº 888/2021 (BRASIL, 2021).

No permeado, a turbidez apresentou valores abaixo do VMP estabelecido pela Portaria GM/MS no 888/2021, de 0,5 uT. Para a cor aparente, os valores de eficiência ficaram entre 96 e 99\%, valor ligeiramente superior ao VMP estabelecido pela Portaria GM/MS n $888 / 2021$, para número de amostras igual a 31. A taxa de rejeição de cor verdadeira ficou entre 66 e $84 \%$. A rejeição de compostos orgânicos, avaliada pela absorvância, ficou entre 34 e 38\%. Lahoussine-Turcaud et al. (1990) encontraram o valor de $27 \%$ de rejeição da absorvância em membrana de ultrafiltração direta (peso molecular de corte de $1.000 \mathrm{~g} \mathrm{~mol}^{-1}$ ) em água do Rio Sena.

Para verificar a influência do aumento da concentração na rejeição do glifosato e do AMPA, realizou-se um ensaio sem alteração do pH da água natural (valores entre 6,2 e 7,1). Os resultados mostraram que o aumento da concentração na alimentação proporcionou aumento da taxa de rejeição do glifosato e do AMPA (Figura 4). A taxa de rejeição do glifosato variou de 30, 33 e 38\% para as concentrações de 630, 800 e $1.250 \mu \mathrm{g} \mathrm{L}^{-1}$, respectivamente. A presença de matéria orgânica contribuiu para rejeição do glifosato em água natural, pois em água destilada a rejeição foi de $24 \%$. Para o AMPA, a rejeição foi inferior a $20 \%$, para a menor concentração, $630 \mu \mathrm{g} \mathrm{L}^{-1}$, bem próximo à rejeição em água destilada (21\%), com valores superiores ao estabelecido na Portaria GM/MS $n^{\circ} 888 / 2021$. A menor rejeição do AMPA pode ser atribuída a sua maior solubilidade e menor massa molar. Somente para a concentração de $630 \mu \mathrm{g} \mathrm{L}^{-1}$ foi produzido efluente com concentrações de glifosato e da somatória de glifosato + AMPA inferiores a $500 \mu \mathrm{g} \mathrm{L}^{-1}$.

Para avaliar a influência do pH na rejeição do glifosato e do AMPA, realizaram-se ensaios com a concentração afluente fixa em $630 \mu \mathrm{g} \mathrm{L}^{-1}$. Em pH natural, a rejeição foi de $27 \%$ para o glifosato, 19\% para o AMPA e $24 \%$ para

Tabela 1 - Características da água de alimentação (água natural), do permeado e valores máximos permitidos (Portaria GM/MS no 888/2021).

\begin{tabular}{l|c|c|c|c} 
Parâmetros & $\begin{array}{c}\text { Alimentação } \\
\text { (min-máx) }\end{array}$ & $\begin{array}{c}\text { Permeado } \\
\text { (min-máx) }\end{array}$ & $\begin{array}{c}\text { Portaria GM/MS no 888/2021 } \\
\text { (VMP) }\end{array}$ & $\begin{array}{c}\text { Rejeição } \\
\text { (min-máx) }\end{array}$ \\
\hline Absorvância $254 \mathrm{~nm}\left(\mathrm{~cm}^{-1}\right)$ & $0,014-0,041$ & $0,0089-0,0262$ & - & $34-37$ \\
\hline Cor aparente $(\mathrm{uH})$ & $115-350$ & $5-16$ & 15 & $96-99$ \\
\hline Cor verdadeira (uH) & $8-21$ & $3-8$ & - & $66-84$ \\
\hline Turbidez (uT) & $6,2-56,6$ & $0,1-0,3$ & 0,5 & $98-99$ \\
\hline $\mathrm{pH}$ & $6,1-7,2$ & $4,2-9,9$ & $6,0-9,5$ & - \\
\hline
\end{tabular}

VMP: valores máximos permitidos.

Fonte: elaboração própria. 
a somatória de glifosato + AMPA (Figura 5). Em pH igual a 10, a rejeição do glifosato aumentou de 27 para 34\% e do AMPA de 19 para 27\%. O aumento do $\mathrm{pH}$ provocou um aumento nas cargas negativas das moléculas do glifosato e do AMPA e consequente aumento na rejeição por interações eletrostáticas entre as moléculas dos microcontaminantes e a membrana. Em pH 4, ocorreu comportamento diverso para o AMPA, que apresentou maior taxa de rejeição quando comparado com o $\mathrm{pH}$ próximo do neutro. Em $\mathrm{pH}$ igual a 4 , os valores no permeado não atenderam ao padrão de potabilidade para o glifosato e o AMPA.

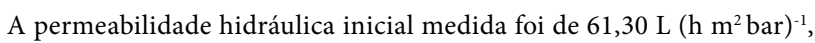
valor superior ao apresentado pelo fabricante, de 42,25 ( $\left.\mathrm{h} \mathrm{m}^{2} \mathrm{bar}\right)^{-1}$ em água ultrapura. Ao longo dos ensaios, ocorreu decréscimo da permeabilidade

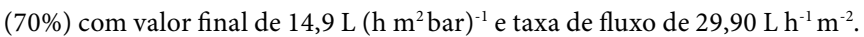
O sistema operou por 1.200 minutos, e nos primeiros 390 minutos as limpezas físicas e químicas tiveram papel importante no restabelecimento do fluxo. Após esse tempo, a perda na taxa de fluxo pode ser atribuída ao depósito de partículas na superfície da membrana, atingindo o estado de colmatação irreversível. Resultados semelhantes foram obtidos por LahoussineTurcaud et al. (1990) tratando água do Rio Sena por ultrafiltração. Os autores atribuíram a MON o decréscimo do fluxo após 300 minutos, ocorrendo a colmatação irreversível.

Na Figura 6, é possível observar a contribuição da matéria orgânica na rejeição do glifosato e do AMPA para concentração de $630 \mu \mathrm{g} \mathrm{L}^{-1}$. A rejeição do glifosato em água destilada foi de $24 \%$ e em água natural variou de 27 a $30 \%$ com valores no permeado sempre inferiores ao estabelecido pela Portaria GM/ MS nº 888/2021. A presença de matéria orgânica interferiu positivamente na

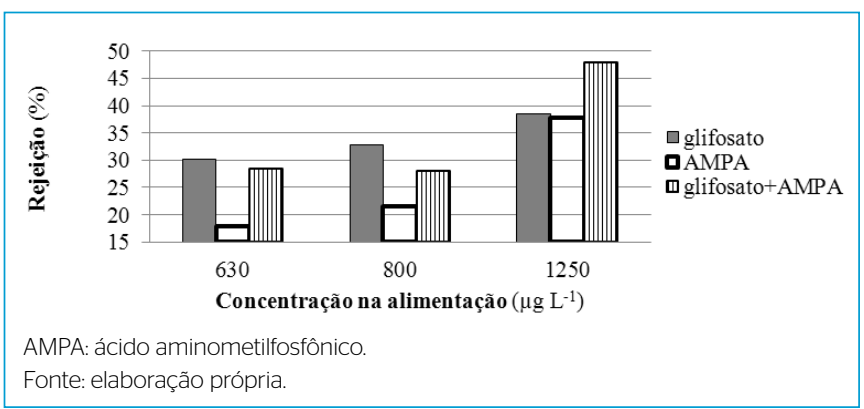

Figura 4 - Rejeição do glifosato, do ácido aminometilfosfônico e da somatória de glifosato + ácido aminometilfosfônico em função da concentração em água natural ( $\mathrm{pH}$ entre 6,1 e 7,2).

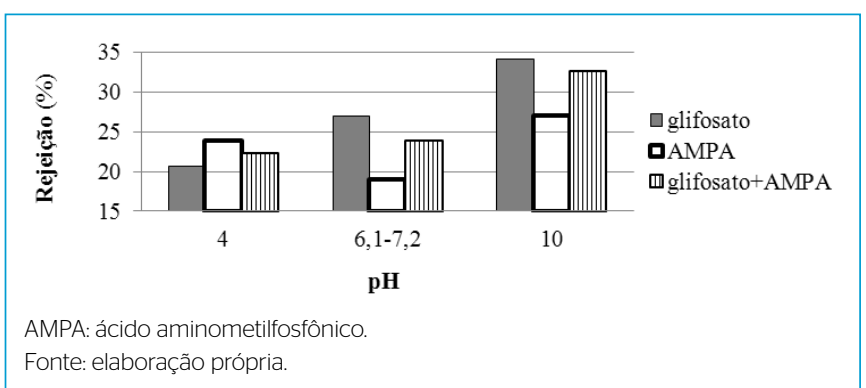

Figura 5 - Efeito da rejeição média do glifosato, do ácido aminometilfosfônico e da somatória do glifosato + ácido aminometilfosfônico em função do $\mathrm{pH}, \mathrm{C}_{\mathrm{o}}$ igual a $630 \mu \mathrm{g} \mathrm{L}^{-1}$, em água natural. rejeição do glifosato e negativamente na rejeição do AMPA. Quando as soluções de glifosato e AMPA foram adicionadas simultaneamente contribuindo cada uma com $50 \%$ da concentração final de $630 \mu \mathrm{g} \mathrm{L}^{-1}$, os valores da somatória de glifosato e AMPA também atenderam ao limite estabelecido pela Portaria GM/MS n $888 / 2021$.

Para avaliar o mecanismo de rejeição dos microcontaminantes por adsorção, realizou-se o balanço de massas para concentração de glifosato e AMPA igual a $630 \mu \mathrm{g} \mathrm{L}^{-1}$ em pH de 4, pH natural e de 10. A massa adsorvida decresceu com o aumento do $\mathrm{pH}$. Com o balanço de massas foi possível verificar que ocorreu adsorção dos compostos na superfície da membrana com massa adsorvida de $1,2 \mu \mathrm{g} \mathrm{cm}^{-2}$ para o glifosato e $1,0 \mu \mathrm{g} \mathrm{cm}^{-2}$ para o AMPA, com respectiva taxa de rejeição de 19 e 16\%, em pH natural. Yoon et al. (2006) verificaram na membrana de ultrafiltração uma relação entre a adsorção de microcontaminantes e o coeficiente de partição octanol/água. Segundo os autores, as substâncias com log Kow $<2,8$ (substâncias hidrofílicas como o glifosato e o AMPA) apresentam tendência pequena para a adsorção $(<25 \%)$. Os valores encontrados ficaram próximos aos valores encontrados por Yoon et al. (2006). Como a rejeição total do glifosato na membrana variou de 27 a 32\%, em pH natural, a rejeição por adsorção (19\%) foi o fenômeno dominante. Outros mecanismos contribuíram na rejeição. Com o aumento do $\mathrm{pH}$, ocorreu aumento da rejeição dos microcontaminantes na membrana e decréscimo da adsorção. Esse comportamento pode explicar a contribuição da repulsão eletrostática considerando que o número de cargas negativas aumenta com o aumento do $\mathrm{pH}$ e a membrana possui também carga negativa.

Com os resultados, avaliou-se a capacidade da membrana de ultrafiltração na rejeição do glifosato e do AMPA. Mesmo a membrana possuindo massa molar de corte de $50.000 \mathrm{~g} \mathrm{~mol}^{-1}$, superior à massa molar do glifosato $\left(169,65 \mathrm{~g} \mathrm{~mol}^{-1}\right)$ e do AMPA $\left(111,00 \mathrm{~g} \mathrm{~mol}^{-1}\right)$, ocorreu rejeição destes. Para concentração do glifosato na alimentação igual a $630 \mu \mathrm{g} \mathrm{L}^{-1}$, no permeado, a concentração foi inferior a $500 \mu \mathrm{g} \mathrm{L}^{-1}$ para os diferentes tipos de água na faixa de pH entre 4 e 10. No permeado, a concentração do AMPA foi sempre superior a $500 \mu \mathrm{g} \mathrm{L-1} \mathrm{em} \mathrm{água} \mathrm{destilada} \mathrm{e} \mathrm{natural} \mathrm{para} \mathrm{variação} \mathrm{do} \mathrm{tempo,} \mathrm{da} \mathrm{concen-}$ tração e do pH. A menor rejeição do AMPA pode ser atribuída a sua maior solubilidade e menor massa molar. Os resultados de rejeição do AMPA são de grande importância, pois não foi encontrada na literatura referência à rejeição do AMPA em membrana de ultrafiltração. Essa observação corrobora a importância de monitoramento do AMPA, considerando que os impactos na saúde são semelhantes aos do glifosato.

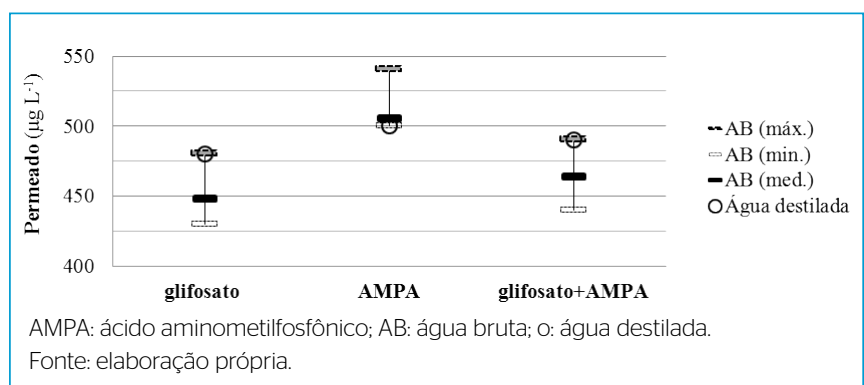

Figura 6 - Concentração do glifosato e do ácido aminometilfosfônico no permeado tendo como afluente água destilada e água bruta, pH entre 6,1 e 7,2 e $\mathrm{C}_{0}$ igual a $630 \mu \mathrm{g} \mathrm{L}^{-1}$. 


\section{CONCLUSÕES}

A ultrafiltração apresentou-se como tecnologia eficiente para tratar água para abastecimento quando se considera os parâmetros turbidez, cor aparente e glifosato.

A eficiência de rejeição foi superior a $98 \%$ para turbidez e $96 \%$ para cor aparente, com valores nominais que atendem à Portaria GM/MS nº 888/2021 (BRASIL, 2021).

Para concentração do glifosato na alimentação de $630 \mu \mathrm{g} \mathrm{L}^{-1}$, foi possível produzir efluente com concentração inferior a $500 \mu \mathrm{g} \mathrm{L}^{-1}$ que é o limite estabelecido pela Portaria GM/MS nº 888/2021, em todas as condições, indicando a possibilidade de utilização da membrana de ultrafiltração na remoção do glifosato.

A ultrafiltração foi efetiva na rejeição do glifosato para a concentração na alimentação de $630 \mu \mathrm{g} \mathrm{L}^{-1}$ para água destilada e água natural, obedecendo ao valor máximo permitido estabelecido na Portaria GM/MS nº 888/2021.

A presença de matéria orgânica influenciou positivamente a rejeição do glifosato e negativamente a rejeição do AMPA e contribuiu para o decréscimo da permeabilidade da membrana.

Para o glifosato, a presença de matéria orgânica e o aumento do $\mathrm{pH}$ e da concentração contribuíram para o aumento da taxa de rejeição.

De acordo com os resultados apresentados pelo balanço de massas, verificou-se efeito dominante da adsorção na rejeição do glifosato e do AMPA, com menor contribuição do fenômeno de atração eletrostática.
O AMPA teve valores de concentrações superiores a $500 \mu \mathrm{g} \mathrm{L}^{-1} \mathrm{em}$ todas as condições, e evidenciou-se a importância de monitoramento do AMPA, pois apresenta impacto na saúde semelhante ao do glifosato.

Os resultados de rejeição do AMPA são de grande importância, pois não se encontrou na literatura referência à rejeição do AMPA em membrana de ultrafiltração.

A membrana de ultrafiltração de polietersulfona pode ser considerada como técnica viável para abatimento de turbidez, de cor aparente e verdadeira e de glifosato em água de abastecimento atendendo à Portaria GM/MS nº 888/2021.

\section{AGRADECIMENTOS}

À Financiadora de Estudos e Projetos (FINEP), o suporte financeiro, e ao Laboratório de Saneamento da Universidade Federal do Espírito Santo.

\section{CONTRIBUIÇÃO DOS AUTORES}

Coelho, E. R. C. C.: conceituação, metodologia, orientação, obtenção de financiamento e administração do projeto, análise dados, supervisão, escrita, revisão e edição. Reis, D. P.: conceituação, metodologia, obtenção e análise dos dados, primeira redação.

\section{REFERÊNCIAS}

AMERICAN PUBLIC HEALTH ASSOCIATION (APHA). Standard methods for the examination of water and wastewater. $12^{\mathrm{a}}$ ed. Washington: American Public Health Association, 2012.

AGÊNCIA NACIONAL DE VIGILÂNCIA SANITÁRIA (ANVISA). Nota técnica no 23/2018/SEI/CREAV/GEMAR/GGTOX/DIRE3/ANVISA. Disponível em: http://portal.anvisa.gov.br/noticias. Acesso em: 22 fev. 2018.

AMARANTE JUNIOR, O. P.; SANTOS, T. C. R.; BRITO, N. M.; RIBEIRO, M. L. Glifosato: propriedades, toxicidade, usos e legislação. Química Nova, v. 25, n. 4, p. 589-593, 2002. https://doi.org/10.1590/SO100-40422002000400014

AVIGLIANO, E.; SCHENONE, N. F. Human health risk assessment and environmental distribution of trace elements, glyphosate, fecal coliform and total coliform in Atlantic Rainforest mountain rivers (South America). Microchemical Journal, v. 122, p. 149-158, 2015. http://doi.org/10.1016/j. microc.2015.05.004

BARBOT, E.; MOUSTIER, S.; BOTTERO, J. Y.; MOULIN, P. Coagulation and ultrafiltration: understanding of the key parameters of the hybrid process. Journal of Membrane Science, v. 325, n. 2, p. 520-527, 2008. https://doi. org/10.1016/j.memsci.2008.07.054

BATTAGLIN, W. A.; THURMAN, E. M., KOLPIN, D. W.; SCRIBNER, E. A.; SANDSTROM, M. W.; KUIVILA, K. M. Work plan for determining the occurrence of glyphosate, its transformation product AMPA, other herbicide compounds, and antibiotics in Midwestern United States streams, 2002. Open-File Report. Reston: U.S. Geological Survey, 2003. 18 p. https://doi.org/10.3133/ofrO369
BRASIL. Ministério da Saúde. Portaria GM/MS no 888, de 4 de maio de 2021. Diário Oficial da República Federativa do Brasil, Poder Executivo, Brasília, DF, 7 maio 2021

CHEN, Y.; XU, W.; ZHU, H.; WEI, D.; HE, F.; DONGSHENG, W.; DU, B.; WEI, Q Effect of turbidity on micropollutant removal and membrane fouling by MIEX/ultrafiltration hybrid process. Chemosphere, v. 216, p. 488-498, 2019 https://doi.org/10.1016/j.chemosphere.2018.10.148

GASNIER, C.; DUMONT, C.; BENACHOUR, N.; CLAIR, E.; CHAGNONB, M. C.; SÉRALINI, G. E. Glyphosate-based herbicides are toxic and endocrine disruptors in human cell lines. Toxicology, v. 262, n. 3, p. 184-191, 2009 https://doi.org/10.1016/j.tox.2009.06.006

GRANDCOIN, A.; PIEL, S.; BAURES, E. AminoMethyIPhosphonic acid (AMPA) in natural waters: its sources, behavior and environmental fate. Water Research, v. 117, p. 187-197, 2017. https://doi.org/10.1016/j.watres.2017.03.055

HANKE, I.; WITTMER, I.; BISCHOFBERGER, S.; STAMM, C.; SINGER, $H$. Relevance of urban glyphosate use for surface water quality. Chemosphere, v. 81, n. 3, p. 422-429, 2010. https://doi.org/10.1016/j. chemosphere.2010.06.067

INSTITUTO BRASILEIRO DO MEIO AMBIENTE E DOS RECURSOS NATURAIS RENOVÁVEIS (IBAMA). Relatórios de comercialização de agrotóxicos. 2016. Disponível em: http://www.ibama.gov.br/agrotoxicos/ relatorios-de-comercializacao-de-agrotoxicos\#sobreosrelatorios. Acesso em: 24 ago. 2020 
JÖNSSON, J.; CAMM, R. O. B.; HALL, T. Removal and degradation of glyphosate in water treatment: a review. Journal of Water Supply: Research and Technology-AQUA, v. 81, n. 7, p. 395-408, 2013. https://doi.org/10.2166/ aqua.2013.080

KIM, S.; CHU, K. H.; AL-HAMADANI, Y. A. J.; PARK, C. M.; JANG, M.; KIM, D. H; MIAO YUE, J.; HEO, J.; YEOMIN, Y. Removal of contaminants of emerging concern by membranes in water and wastewater: a review. Chemical Engineering Journal, v. 335, p. 896-914, 2018. https://doi.org/10.1016/j. cej.2017.11.044

LAUTENSCHLAGER, S. R.; FERREIRA FILHO, S. S; PEREIRA, O. Modelação matemática e otimização operacional de processos de membrana de ultrafiltração. Engenharia Sanitária Ambiental, v. 14, n. 2, p. 215-222, 2009. https://doi.org/10.1590/S1413-41522009000200009

LAHOUSSINE-TURCAUD, V.; WIESNER, M. R.; BOTTERO, J. Y. Fouling in tangential-flow ultrafiltration: the effect of colloid size and coagulation pretreatment. Journal of Membrane Science, v. 52, n. 2, p. 173-190, 1990. https://doi.org/10.1016/SO376-7388(00)80484-6

LIU, M., HATA, A.; KATAYAMA, H.; KASUGA, I. Consecutive ultrafiltration and silica adsorption for recovery of extracellular antibiotic resistance genes from an urban river. Environmental Pollution, v. 260, p. 1-9, 2020. https://doi. org/10.1016/j.envpol.2020.114062

LI, Z.; JENNINGS, A. Worldwide regulations of standard values of pesticides for human health risk control: a review. International Journal of Environmental Research and Public Health, v. 14, n. 7, p. 826, 2017. https://doi. org/10.3390/ijerph14070826

MEFFE, R., BUSTAMANTE, I. Emerging organic contaminants in surface water and groundwater: a first overview of the situation in Italy. Science of the Total Environment, v. 481, p. 280-295, 2014. https://doi.org/10.1016/j. scitotenv.2014.02.053

MIERZWA, J. C.; HESPANHOL, I.; SILVA, M. C. C.; RODRIGUES, L. D. B.; GIORGI, C. F. Direct drinking water treatment by spiral-wound ultrafiltration membranes, Desalination, v. 230, n. 1, p. 41-50, 2008. http://doi.org/10.1016/j. desal.2007.11.014
MONSANTO. (Org.). Segurança do glifosato. 2016. Disponível em: http:// www.monsanto.com/global/br/produtos/pages/seguranca-glifosato.aspx Acesso em: 01 jun. 2016

SANTOS, A. L. Z. Avaliação do tratamento de efluentes sintéticos com glifosato por osmose inversa. 119 f. Dissertação (Mestrado em Química) - Centro de Ciências e Tecnologia, Universidade do Estado do Rio de Janeiro, Rio de Janeiro, 2013.

SANTOS, T. T. S.; MELO, A. P. S.; SANTOS, D. M.; COSTA, A. S; MARQUES, M. N. Determinação do AMPA e glifosato em água de abastecimento público na cidade de Aracaju pela técnica de cromatografia de íons. In: VI Encontro de Recursos Hidricos em Sergipe, 2013, Aracaju.

SANTOYO, G. A.; LLANOS, J:; RASCHITOR, J.; BUSTOS, E.; CAÑIZARES, P.; RODRIGO, M. A. Performance of ultrafiltration as a pre-concentration stage for the treatment of oxyfluorfen by electrochemical BDD oxidation. Separation and Purification Technology, v. 237,2020. https://doi.org/10.1016/j.seppur.2019.116366

SILVA, M. D.; PERALBA, M. C. R.; MATTOS, M. L. T. Determinação de glifosato e ácido Aminometilfosfônico em águas superficiais do Arroio Passo do Pilão. Pesticidas: R.Ecotoxicol. e Meio Ambiente, Curitiba, v. 13, 2003. http:// doi.org/10.5380/pes.v13iO.3161

SPETH, T. F. Glyphosate removal from drinking water. Asce Manager of Journals, Journal of Environmental Engineering, v. 119, n. 6. p. 1139-1157, 1993 https://doi.org/10.1061/(asce)0733-9372(1993)119:6(1139)

UYAK, V.; AKDAGLI, M.; CAKMAKCI, M.; KOYUNCU, I. Natural Organic Matter Removal and Fouling in a Low-Pressure Hybrid Membrane Systems. The Scientific World Journal, p. 1-11, 2014. https://doi.org/10.1155/2014/893203

YOON, Y.; WESTERHOFFB, P.; SNYDERC, S.; WERTC, E. Nanofiltration and ultrafiltration of endocrine disrupting compounds, pharmaceuticals and personal care products. Journal of Membrane Science, v. 270, n. 1-2, p. 88100, 2006. https://doi.org/10.1016/.j.memsci.2005.06.045

WILLIAMS, G. M.; KROES, R.; MUNRO, I. C. Safety Evaluation and Risk Assessment of the Herbicide Roundup and Its Active Ingredient, Glyphosate, for Humans. Regulatory Toxicology and Pharmacology, v. 31, p. 117-165, 2000. https://doi.org/10.1006/rtph.1999.1371 